\title{
Whither hepatocellular carcinoma in sub-Saharan Africa?
}

\section{Où va le cancer primitif du foie en Afrique subsaharienne ?}

\author{
M.C. Kew \\ Revised: 26 November 2010 , Accepted: 20 December 2010 \\ (C) Springer-Verlag France 2011
}

Hepatocellular carcinoma (HCC) occurs commonly in the Black population of sub-Saharan Africa. Approximately 46,000 new cases of primary liver cancer are diagnosed in Africa each year, of which more than $90 \%$ are HCCs [1,2]. The highest incidences of the tumour are recorded in middle and western Africa [1], although Mozambique in eastern Africa also has a very high incidence [3]. Not only does HCC occur commonly in sub-Saharan Africa, it also carries a particularly grave prognosis and is among the three most common causes of cancer deaths. As disturbing as these figures undoubtedly are, they underestimate the true incidence and mortality rate of HCC because many patients with this tumour are not definitively diagnosed and do not enter the record books. The main reasons for this unsatisfactory state of affairs are the inadequate medical and diagnostic facilities in rural areas, where the majority of cases occur. In addition, few sub-Saharan countries have reliable cancer registries.

With the paucity of medical facilities in the rural areas of the subcontinent and the often rapid growth rate of HCC in this population [4], the patients frequently present to the doctor only when the tumour has reached an advanced stage. Because of the high incidence of $\mathrm{HCC}$, medical practitioners in Africa are usually mindful of this tumour. Nevertheless, definitive diagnosis is hampered by the lack of diagnostic facilities. Even the measurement of the serum $\alpha$-fetoprotein level, a very useful indicator of the presence of HCC in black African populations [5,6], is usually performed only in urban laboratories. Moreover, the sophisticated imaging equipment now used in the diagnosis of HCC in the industrialized countries [7] may not to be available in sub-Saharan Africa, even in urban hospitals. In addition, treatment options are limited.

These limitations to the early recognition and options of treatment of HCC in sub-Saharan Africa contrast with the increased accuracy of diagnosis of $\mathrm{HCC}$ and the greater

\footnotetext{
M.C. Kew ( $\square)$

Department of Medicine, University of Cape Town and Groote Schuur Hospital, Cape Town, and Department of Medicine, University of the Witwatersrand, Johannesburg, South Africa e-mail : michael.kew@uct.ac.za
}

opportunities for treating the tumour now possible in developed countries [8-12]. More patients in these countries are now having the tumour resected [8-10]. More importantly, great strides have recently been made in assessing the suitability of patients for liver transplantation and in achieving better results with this operation $[8,9,11]$. Even if the HCC is initially deemed to be inoperable, it may be possible to 'down-stage' the tumour using radio-frequency ablation, ablation with the injection of alcohol, or trans-arterial chemoembolization, and render the tumour amenable to surgical intervention [12]. For those patients with surgically incurable tumours, sophisticated new radiotherapeutic techniques in the form of three-dimensional high-dose photon beam radiotherapy [13] or stereotactic radiotherapy [14,15] can accurately confine the rays to the tumour tissue, sparing the adjacent liver tissue, and thereby achieving far better results than were hitherto possible. Furthermore, the multikinase inhibitor, sorafenib, has recently been shown to prolong survival in patients with inoperable HCC [16].

There are, therefore, compelling reasons why we should ask ourselves: Whither hepatocellular carcinoma in subSaharan Africa?

Theoretically, two options are available for rectifying the current highly unsatisfactory state of diagnosis and treatment of HCC in sub-Saharan Africa - either prevent the tumour or raise the standards of diagnosis and treatment to the level now available in developed countries.

Is prevention of HCC possible in sub-Saharan Africa? The answer is yes in the long term, but no in the short term. The great majority of HCCs in sub-Saharan black Africans are caused by chronic hepatitis B virus (HBV) infection. Other important causes are dietary exposure to the fungal toxin, aflatoxin $\mathrm{B}_{1}$, and chronic hepatitis $\mathrm{C}$ infection, both of which can act synergistically with $\mathrm{HBV}$ in causing HCC, and African dietary iron overload. Eradication of chronic HBV infection, and hence the prevention of the great majority of HCCs in the sub-continent, as a result of universal immunization of all infants against the virus is an exciting and obtainable goal. A safe and effective vaccine against HBV has been available since the early 1980s and, with 
one exception, all sub-Saharan African countries have now included this vaccine in their Expanded Program of Immunization (information courtesy of the World Health Organization). In Taiwan, where comprehensive vaccine cover has long been achieved, the incidence of HCC has already decreased by $70 \%$ in those immunized [17]. Unfortunately, in a number of sub-Saharan African countries, logistic reasons have prevented the full course of immunization being completed with the result that maximal protection has not been provided. This, together with the known prolonged interval between infection with the virus and the development of HCC, means that it will take between 30 and 50 years for HBV-induced HCC in the subcontinent to be completely prevented. In addition, there is no immediate prospect of a vaccine against the hepatitis $C$ virus becoming available. Feasible measures to prevent aflatoxin $B_{1}$ exposure and dietary iron overload are known, but no programmes are yet in place. Thus, for the foreseeable future, HCC will continue to occur with a high frequency in the black population of sub-Saharan Africa.

That leaves, for the interim, the second option, which is that steps must be taken to ensure that sub-Saharan patients with $\mathrm{HCC}$ receive the benefits of the improved diagnosis and treatment of HCC now available in developed countries. This will require a concerted effort, at several levels, and considerable funding from governmental and non-governmental agencies and other sources to allow the establishment of well-equipped and staffed centres of excellence in subSaharan Africa where the diagnosis of HCC can be made and appropriate treatment undertaken. These centres should be comparable with those in resource-rich countries. Steps will also have to be taken to ensure that rural patients have ready and speedy access to these centres.

This is a great deal to ask for, but it is the only way, in the foreseeable future, to offer some hope to the many black Africans currently dying from HCC.

\section{References}

1. Parkin DM, Pisani P, Ferlay J (1999) Estimates of worldwide incidences of 25 major cancers. Int J Cancer 80: 827-841

2. Parkin DM, Ferlay J, Hamdi-Sarif J, et al (2003) Cancer in Africa: Epidemiology and prevention. IARC Scientific Publications $\mathrm{N}^{\circ} 153$, Lyon, IARC Press

3. Prates MD, Torres FO (1965) A cancer survey in Portuguese East Africa. J Natl Cancer Inst 35:729-57

4. Purves LR (1976) Alpha-fetoprotein and the diagnosis of liver cell cancer. In: Cameron HM, Linsell DA, Warwuick GP (eds) Liver cell cancer. Elsevier, Amsterdam, pp 61-80

5. Alpert E (1976) Human $\alpha$-fetoprotein. In: Okuda K, Peters RL (eds) Hepatocellular carcinoma. Wiley, New York, pp 353-9

6. Kew MC (1989) Tumor markers in hepatocellular carcinoma. J Gastroenterol Hepatol 4:373-84

7. Lencioni R (2010) Evolving strategies in the diagnosis of hepatocellular carcinoma. J Hepatol, Epub ahead of print

8. Mendizabal M, Reddy KR (2009) Current management of hepatocellular carcinoma. Med Clin N Amer 93:885-900

9. Singal AG, Marrero JA (2010) Recent advances in the treatment of hepatocellular carcinoma. Curr Opin Gastroenterol 26:189-95

10. Delis DG, Bakoyiannis A, Tassopoulos H, et al (2009) Hepatic resection for hepatocellular carcinoma in the era of the USCF criteria. HPB (Oxford) 11:551-8

11. Tsoulfas G, Kawai T, Elias N, et al (2010) Long-term experience with liver transplantation for hepatocellular carcinoma. J Gastroenterol, Epub ahead of print.

12. Toso C, Mentha G, Kneteman NM, Majno P (2010) The place for down-staging for hepatocellular carcinoma. J Hepatol 52:930-6

13. Merle P, Mornex F, Trepo C (2009) Innovative therapy for hepatocellular carcinoma: three-dimensional high-dose photon radiotherapy. Cancer Lett 286:29-33

14. Lo SS, Dawson LA, Kim EY, et al (2010) Stereotactic body radiation therapy for hepatocellular carcinoma. Discov Med 9:404-10

15. Kwon JH, Bae SH, Kun JY, et al (2010) Long-term effect of stereotatic radiation therapy for primary hepatocellular carcinoma ineligible for local ablation treatment or surgical resection. BMC Cancer 10:475-84

16. Llovet JM, Ricci S, Mazzaferro V, et al (2008) Sorafenib in advanced hepatocellular carcinoma. N Engl J Med 359:378-90

17. Chang MH, You SL, Chen CJ, et al (2009) Decreased incidence of hepatocellular carcinoma in hepatitis B vaccinees: a 20 -year follow-up. J Natl Cancer Inst 101:1348-55 